\title{
Antisocial Personality Disorder
}

National Cancer Institute

\section{Source}

National Cancer Institute. Antisocial Personality Disorder. NCI Thesaurus. Code C88413.

A disorder characterized by a pervasive pattern of disreg ard for and violation of the rights of others that is manifested in childhood or early adolescence. (adapted from DSM-IV) 